\title{
Coil Ambient Temperature and Its Influence on the Formation of Blocking Layer in the Electromagnetic Induction-Controlled Automated Steel-Teeming System
}

\author{
Ming $\mathrm{He}^{1,2} \cdot$ Xian-Liang $\mathrm{Li}^{1,3} \cdot$ Xing-An Liu ${ }^{1} \cdot$ Xiao-Wei Zhu ${ }^{1,2} \cdot$ Tie Liu $^{1} \cdot$ Qiang Wang $^{1}$ \\ Received: 10 September 2018/Revised: 21 September 2018/Published online: 12 October 2018 \\ (c) The Chinese Society for Metals and Springer-Verlag GmbH Germany, part of Springer Nature 2018
}

\begin{abstract}
Ambient temperature of induction coil is an important factor to influence the implementation of the electromagnetic induction-controlled automated steel-teeming (EICAST) technology. Meanwhile, it also affects the formation of $\mathrm{Fe}-\mathrm{C}$ alloy blocking layer, which determines the length and installation position of induction coil. An experimental platform was designed to imitate actual working conditions in a ladle with the EICAST system. Ambient temperature of induction coil under high-temperature condition was measured to verify the accuracy of numerical result. After containing molten steel for $120 \mathrm{~min}$ and steel teeming for $40 \mathrm{~min}$, the ambient temperature on the upper side of induction coil is $791{ }^{\circ} \mathrm{C}$. In addition, the position of blocking layer in a $110 \mathrm{t}$ ladle was measured by sand-collection and steel-pour methods, and the criterion temperatures of blocking layer in numerical simulation process were corrected. When the refining temperature is $1600{ }^{\circ} \mathrm{C}$ and the containing time of molten steel is $120 \mathrm{~min}$, the thickness of blocking layer is $130 \mathrm{~mm}$, and the distance between the upper surface of blocking layer and the upper surface of nozzle brick is $154 \mathrm{~mm}$. When the criterion temperatures are $919^{\circ} \mathrm{C}$ and $428^{\circ} \mathrm{C}$, the numerical results can be used to confirm the position of blocking layer and the installation position of induction coil.
\end{abstract}

Keywords Clean steel $\cdot$ EICAST technology $\cdot$ Heat transfer $\cdot$ Blocking layer $\cdot$ Coil ambient temperature

\section{Introduction}

Steel with excellent work performance is the ultimate goal for many metallurgical scholars and steel enterprises [1]. Steel cleanliness has a significant effect on the steel microstructure, which further affects the ultimate performance of steel $[2,3]$. After proposing the concept of clean steel, many clean steel production technologies are put forward and industrialized to reduce inclusion content and

Available online at http://link.springer.com/journal/40195

Qiang Wang

wangq@mail.neu.edu.cn

1 Key Laboratory of Electromagnetic Processing of Materials (Ministry of Education), Northeastern University,

Shenyang 110819, China

2 School of Metallurgy, Northeastern University, Shenyang 110819, China

3 School of Materials Science and Engineering, Northeastern University, Shenyang 110819, China size in steel, such as the hot metal desulphurization, the top and bottom combined converter blowing, the slag detection, and the argon stirring [4-7]. During the steel-teeming process, the removal or optimization of nozzle sand is a hot research topic of clean steel production. In a sliding gate system, the nozzle sand, a foreign inclusion, will drop into a tundish within molten steel. Studies have shown that the number of large-size $\mathrm{Al}_{2} \mathrm{O}_{3}$ inclusions in molten steel will decrease after pouring into the tundish from the ladle [8]. The number of small-size $\mathrm{Al}_{2} \mathrm{O}_{3}$ inclusions will increase obviously at that process, and the mixture of nozzle sand and other refractory materials is an important reason. To reduce the nozzle sand dropped into the tundish, many metallurgical workers have carried out lots of research works [9, 10]. Typically, Yang [9] puts forward a new method of setting a recovery device of nozzle sand near the lower nozzle. After opening the lower slide gate, the recovery device is moved to the position, where the nozzle sand falls. Liu [10] proposed a new method of using highpressure gas under the lower nozzle to blow the nozzle sand away from long nozzle or tundish. Although the two 
methods mentioned above can reduce the nozzle sand dropped into the tundish, their operation is inconvenient to control, and they will affect the pace of automatic production seriously. More serious problem is that they will increase the possibility of production accidents.

The automatic free-opening rate is also another important factor affecting the automated production in steel enterprises [11-13]. For crude steel in continuous casting production, the automatic free-opening rate can reach about $98 \%$. However, the automatic free-opening rate of special steel is only about $80 \%$. When the ladle is not opened automatically, an oxygen burning method will be applied to assist the opening. This will not only disturb the production rhythm, but also cause the secondary oxidation of molten steel. The reasons for the failure of automatic free opening include the filling state, the composition and particle shape of nozzle sand $[14,15]$. It is found that the automatic free-opening rate of ladle can be increased by improving the filling state of nozzle sand in the nozzle, optimizing the composition of nozzle sand, or improving the masonry structure at the bottom of ladle, but it is difficult to increase the automatic free-opening rate greatly or even to $100 \%$ [16-18].

An electromagnetic induction-controlled automated steel-teeming (EICAST) technology has attracted much attention, because it can solve the problems mentioned above in the sliding gate system [19-21]. In the EICAST system, $\mathrm{Fe}-\mathrm{C}$ alloy particle is used as a new filling material to replace nozzle sand. The composition of $\mathrm{Fe}-\mathrm{C}$ alloy is similar to that of liquid steel. After pouring high-temperature molten steel into ladle, $\mathrm{Fe}-\mathrm{C}$ alloy particles in the upper nozzle will be divided into four layers from top to bottom because of heat transfer from molten steel. They are the melted layer, liquid-sintered layer, solid-sintered layer, and original layer, respectively. Liquid-sintered layer and solid-sintered layer have contribution to block liquid steel, known as the blocking layer [22]. When the ladle is placed at the pouring position, the process is to melt whole or part $\mathrm{Fe}-\mathrm{C}$ blocking layer by Joule heat generated by induction coil. Electromagnetic induction heating is applied in the steel-teeming process by the EICAST technology successfully. This method can avoid using nozzle sand. And the automatic free-opening rate can also reach $100 \%$ by this new technology.

The feasibility of the EICAST technology was verified by laboratory experiments [23]. To apply this new technology in the industrial production, a large number of numerical simulations had been carried out [24]. Design and operating parameters of the EICAST system aimed at a large ladle were determined and calculated. Safety and reliability of the new ladle with the EICAST system were also investigated. However, during the industrial tests, whether the coil material is pure copper or $\mathrm{Cu}-0.6 \mathrm{Cr}-0.2 \mathrm{Zr}$ alloy [25], ambient temperature affects the working performance of induction coil seriously, and it also affects coil structure design and insulation method. Induction coil cannot be cooled by water because it is located at the bottom of ladle. In addition, the coil ambient temperature also affects the formation of $\mathrm{Fe}-\mathrm{C}$ alloy blocking layer, which is directly related to the length and installation position of induction coil. Therefore, it is necessary to measure the coil ambient temperature, and the position and thickness of $\mathrm{Fe}-\mathrm{C}$ alloy blocking layer by experiments.

In this work, a large experimental platform was designed to imitate the actual working conditions of the EICAST system, and the coil ambient temperatures were measured. Moreover, the position of $\mathrm{Fe}-\mathrm{C}$ alloy blocking layer in a $110 \mathrm{t}$ ladle were measured by sand-collection method and steel-pour method. Finally, the experimental results were compared with simulation results. These studies are helpful to analyze the length and installation position of induction coil and to promote the industrial application of the EICAST system.

\section{Experimental}

\subsection{Design of Experimental Platform}

In the EICAST system, induction coil is directly embedded in nozzle brick at the bottom of the ladle. As a new filling material, the $\mathrm{Fe}-\mathrm{C}$ alloy particles are placed into the upper nozzle before containing molten steel. Because of heat transfer from molten steel, $\mathrm{Fe}-\mathrm{C}$ alloy particles will form a blocking layer. At the same time, the ambient temperature of the induction coil will increase gradually, which affects the service life of the induction coil. To imitate the actual

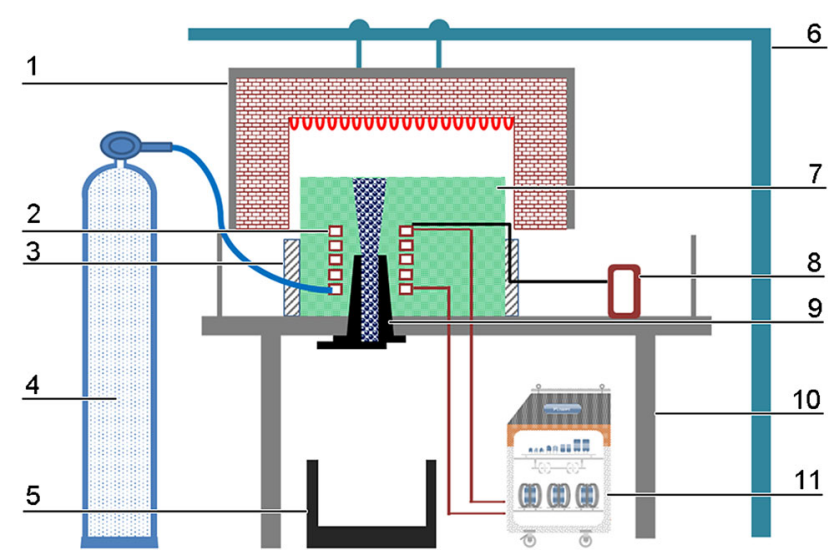

Fig. 1 Schematic illustration of electromagnetic steel-teeming experimental devices. 1-resistance furnace; 2-induction coil; 3 - thermal insulation material; 4-compressed air; 5-collecting device; 6support structure; 7-nozzle brick; 8-K thermocouple; 9-upper nozzle; 10 - experimental platform; 11-induction power supply 
working conditions in the ladle, a large experimental platform is designed, as shown in Fig. 1. The nozzle brick with an induction coil used in this device has the same size and material with the nozzle brick used in the ladle of a steel plant. By resistance heating, the upper surface temperature of nozzle brick can reach $1600{ }^{\circ} \mathrm{C}$, which is used to simulate the high temperature from liquid steel. Heating curve is designed according to the operation process of the ladle in the steel plant. According to the heating curve, the upper surface of nozzle brick is heated and maintained high temperature for a period of time. At that time, the coil ambient temperatures can be measured.

During the experimental process, the $\mathrm{Fe}-\mathrm{C}$ alloy particles were filled in the upper nozzle firstly, and the composition of $\mathrm{Fe}-\mathrm{C}$ alloy particles is shown in Table 1. Then, the resistance furnace was fallen to a fixed position. At that time, the distance between the upper surface of nozzle brick and heating elements in resistance furnace was $15 \mathrm{~mm}$. Four sides of nozzle brick were wrapped by heat preservation material of thickness $80 \mathrm{~mm}$. Finally, the resistance furnace was turned on. After that, the upper surface temperature of nozzle brick reached $1600{ }^{\circ} \mathrm{C}$ and maintained $120 \mathrm{~min}$, and the temperature on the upper side of induction coil was measured by a $\mathrm{K}$ thermocouple.

\subsection{Sand-Collection Method and Steel-Pour Method}

In order to measure the position and thickness of $\mathrm{Fe}-\mathrm{C}$ alloy blocking layer in the $110 \mathrm{t}$ ladle used in the steel plant, as shown in Figs. 2 and 3, sand-collection method and steel-pour method were proposed. Different steel grades need different refining temperatures. Therefore, the selected refining temperatures were $1500{ }^{\circ} \mathrm{C}$ and $1600{ }^{\circ} \mathrm{C}$ in experiments, respectively. The composition of $\mathrm{Fe}-\mathrm{C}$ alloy particles is also shown in Table 1 .

By using sand-collection method, the lower surface position of $\mathrm{Fe}-\mathrm{C}$ alloy blocking layer can be calculated by original $\mathrm{Fe}-\mathrm{C}$ alloy particles collected after opening the sliding gate. As shown in Fig. $2 \mathrm{~b}$, the original $\mathrm{Fe}-\mathrm{C}$ alloy particles were collected and placed in a measuring device, and then, the values of $d_{1}$ and $d_{2}$ were measured. The length of the measuring ruler and total height of $\mathrm{Fe}-\mathrm{C}$ alloy are $d_{1}$, and its value is $515 \mathrm{~mm}$. The height of $\mathrm{Fe}-\mathrm{C}$ alloy original layer is $d_{2}$, so the lower surface position of $\mathrm{Fe}-\mathrm{C}$ alloy blocking layer can be determined by $d_{2}$.

In the steel-pour method, the molten steel in ladle after normal operation is poured into another empty ladle, the melting layer of $\mathrm{Fe}-\mathrm{C}$ blocking layer will flow out with the molten steel, and then the upper surface position of $\mathrm{Fe}-\mathrm{C}$ alloy blocking layer can be measured directly, as shown in Fig. 3. In measuring stage, two pipes of length of $10 \mathrm{~m}$ through a fixed support were put into the upper nozzle and the nozzle brick, respectively. Length difference $D_{1}$ is the distance between the upper surface of nozzle brick and the upper surface of $\mathrm{Fe}-\mathrm{C}$ alloy blocking layer, which can characterize the thickness of $\mathrm{Fe}-\mathrm{C}$ alloy melted layer. At the same time, another two pipes of length of $1 \mathrm{~m}$ through a fixed support were put into the upper nozzle and the bottom shell of ladle, respectively. Length difference $D_{2}$ is the distance between the lower surface of $\mathrm{Fe}-\mathrm{C}$ alloy blocking layer and the bottom shell of ladle, which can characterize the thickness of $\mathrm{Fe}-\mathrm{C}$ alloy original layer. The distance between the upper surface of nozzle brick and the bottom shell of ladle is $D_{0}$. Thus, the thickness of $\mathrm{Fe}-\mathrm{C}$ alloy blocking layer can be calculated by $D_{0}-D_{1}-D_{2}$.

\section{Numerical Simulation}

Finite element analysis model in numerical simulation was built according to the actual nozzle brick and induction coil, as shown in Fig. 4a. Relevant dimensions are shown in Fig. 4b. After the ladle with the EICAST system runs several cycles, the temperature distribution inside nozzle brick reaches thermal saturation and the coil ambient temperature reaches maximum value.

Because of the complexity of the EICAST system, some necessary assumptions are as follows:

1. The material of the upper nozzle is the same as that of nozzle brick, and the gap between the upper nozzle and nozzle brick is neglected.

2. The composition of $\mathrm{Fe}-\mathrm{C}$ alloy particles is the same as that of molten steel. The $\mathrm{Fe}-\mathrm{C}$ alloy particles are well packed in the upper nozzle, and the gaps between $\mathrm{Fe}-\mathrm{C}$ alloy particles are neglected.

3. When calculating the ambient temperature of induction coil and the position of $\mathrm{Fe}-\mathrm{C}$ alloy blocking layer, the upper surface temperature of nozzle brick is $1600{ }^{\circ} \mathrm{C}$; during the steel-teeming period, the upper surface temperature of nozzle brick and the inner surface of the upper nozzle are $1600{ }^{\circ} \mathrm{C}$.

4. Because the induction coil moves along with the ladle before steel teeming, the coil is not cooled by forced air cooling, so induction coil is filled with still air, and the convective coefficient of still air is $5 \mathrm{~W} /\left(\mathrm{m}^{2}{ }^{\circ} \mathrm{C}\right)$.
Table 1 Composition of $\mathrm{Fe}-\mathrm{C}$ alloy particles

\begin{tabular}{llllllll}
\hline Fe-C alloy & $\mathrm{C}$ & $\mathrm{Si}$ & $\mathrm{Mn}$ & $\mathrm{P}$ & $\mathrm{S}$ & $\mathrm{Cu}$ & $\mathrm{Ni}$ \\
\hline Components & $0.07-0.13$ & $0.17-0.37$ & $0.35-0.65$ & $\leq 0.035$ & $\leq 0.035$ & $\leq 0.25$ & $\leq 0.25$ \\
\hline
\end{tabular}




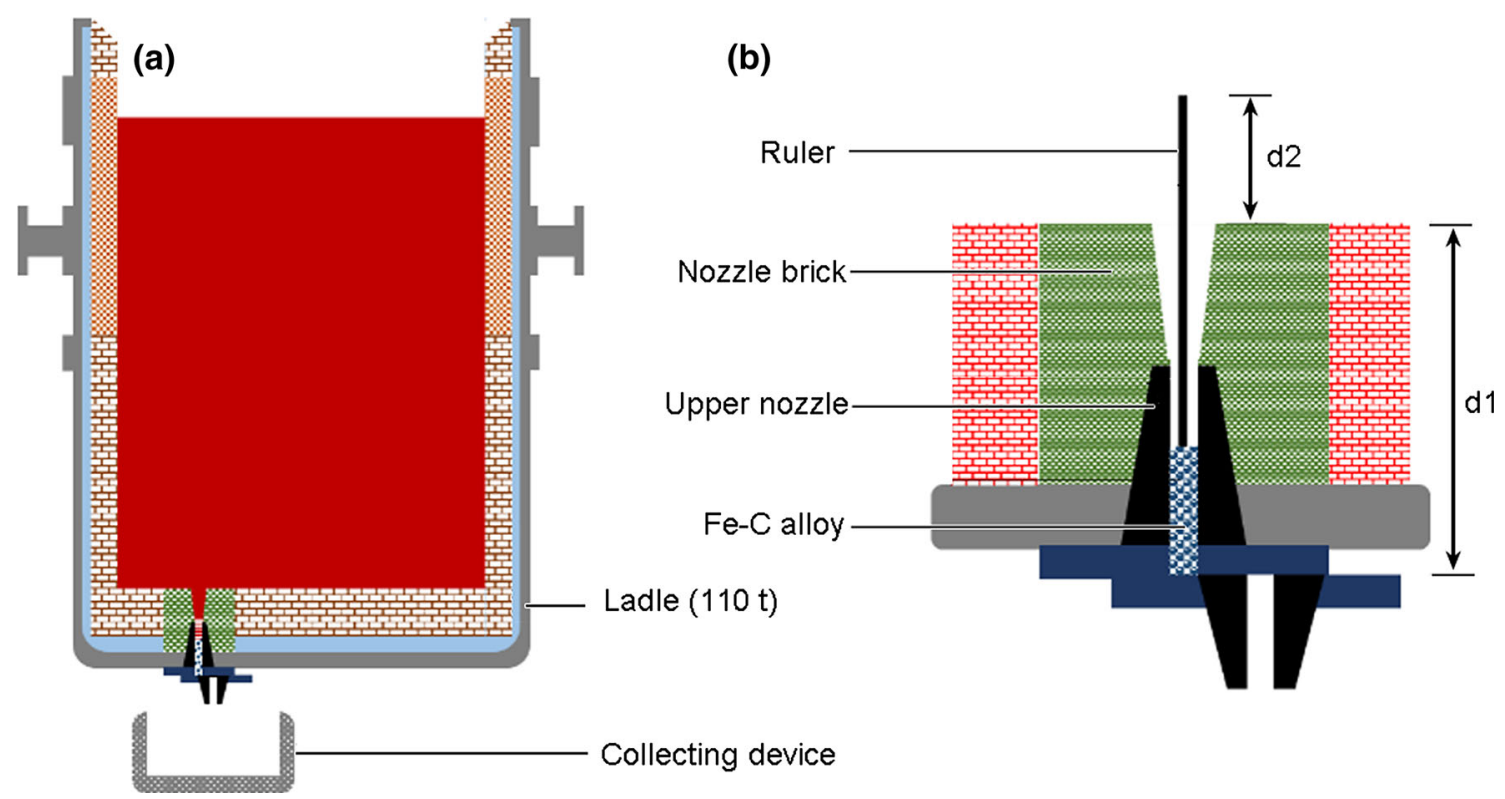

Fig. 2 Schematic illustration of sand-collection method: a collecting device, $\mathbf{b}$ measuring device

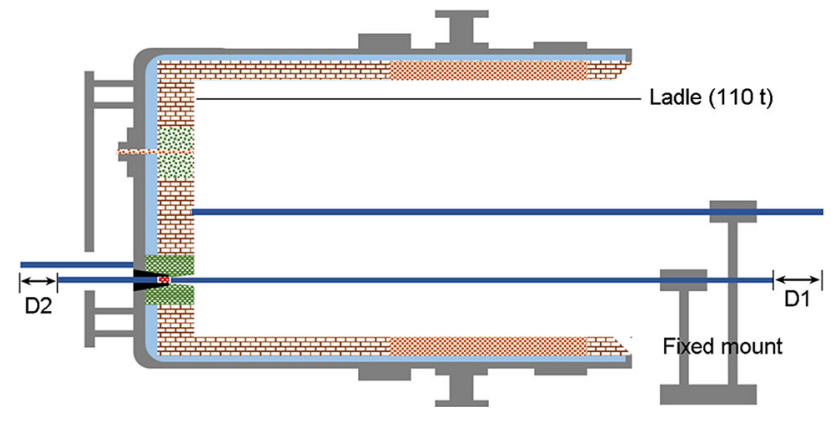

Fig. 3 Schematic illustration of steel-pour method

Four sides of nozzle brick are adiabatic; there is thermal convection between the lower surface of nozzle brick and air, and the convective coefficient is $15 \mathrm{~W} /\left(\mathrm{m}^{2}{ }^{\circ} \mathrm{C}\right)$.

Physical parameters of all materials are shown in Table 2. As seen in Ref. [26], the specific heat capacity of

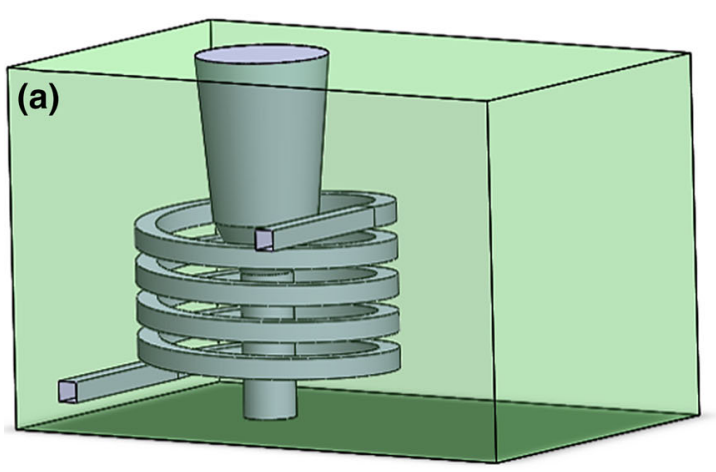

high alumina refractories is very little affected by temperature, so the specific heat capacity of nozzle brick is $1.13 \mathrm{~kJ} \mathrm{~kg}^{-1}{ }^{\circ} \mathrm{C}^{-1}$. The relationship between the thermal conductivity and temperature of nozzle brick is $\lambda=2.9+0.00019 T$, and the influence of temperature on the thermal conductivity is very small. Therefore, the selected thermal conductivity of nozzle brick is $2.9 \mathrm{~W} \mathrm{~m}^{-1}{ }^{\circ} \mathrm{C}^{-1}$. The specific heat capacity and thermal conductivity of $\mathrm{Fe}-\mathrm{C}$ alloy at different temperatures are shown in Fig. 5. Similarly, the specific heat capacity and thermal conductivity of copper coil at different temperatures are shown in Fig. 6 [27].

For the three-dimensional heat conduction problem, the temperature distribution in the nozzle brick can be calculated by the following equation:

$$
\rho c \frac{\partial T}{\partial \tau}=\frac{\partial}{\partial x}\left(\lambda \frac{\partial T}{\partial x}\right)+\frac{\partial}{\partial y}\left(\lambda \frac{\partial T}{\partial y}\right)+\frac{\partial}{\partial z}\left(\lambda \frac{\partial T}{\partial z}\right)+q_{\mathrm{v}}
$$

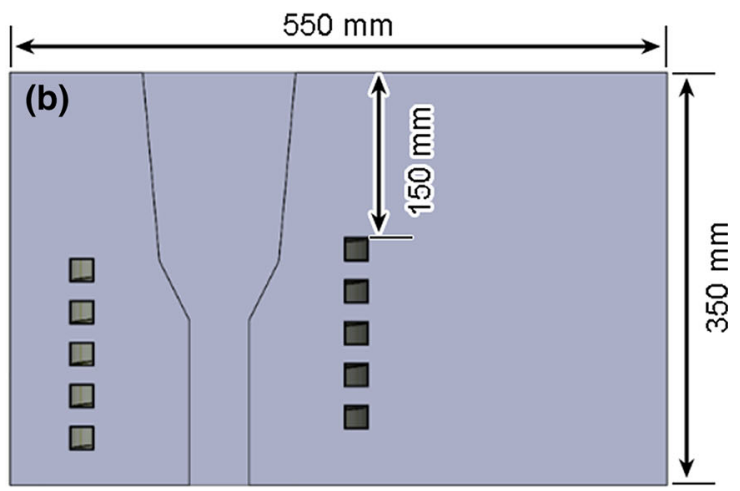

Fig. 4 Simulation model: a three-dimensional model, $\mathbf{b}$ relevant dimensions 
Table 2 Physical parameters of several materials

\begin{tabular}{|c|c|c|c|}
\hline Materials & Density $\left(\mathrm{kg} \mathrm{m}^{-3}\right)$ & Specific heat capacity $\left(\mathrm{kJ} \mathrm{kg}^{-1}{ }^{\circ} \mathrm{C}^{-1}\right)$ & Thermal conductivity $\left(\mathrm{W} \mathrm{m}^{-1}{ }^{\circ} \mathrm{C}^{-1}\right)$ \\
\hline Nozzle brick & 3040 & 1.13 & 2.9 \\
\hline $\mathrm{Fe}-\mathrm{C}$ alloy & 7830 & Fig. 5 & Fig. 5 \\
\hline Coil (copper) & 8930 & Fig. 6 & Fig. 6 \\
\hline
\end{tabular}

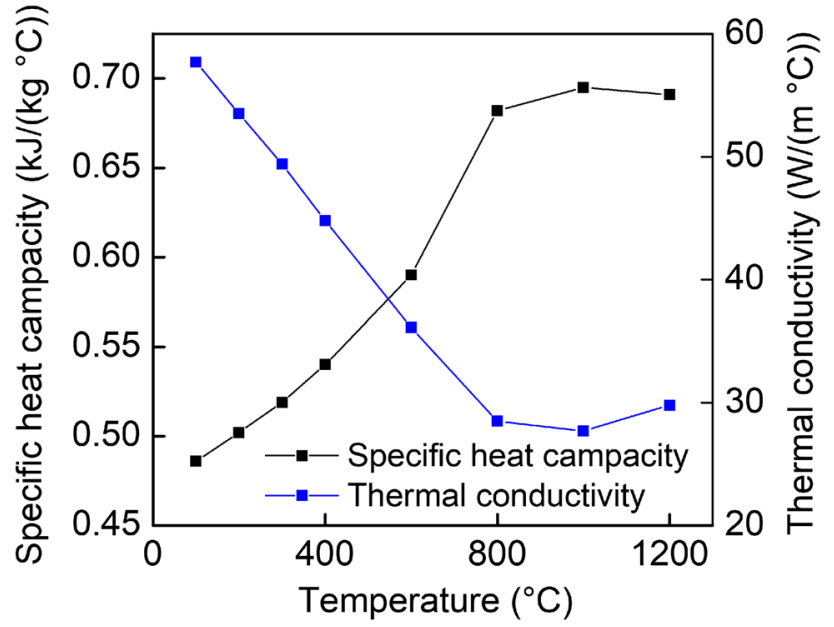

Fig. 5 Specific heat capacity and thermal conductivity of $\mathrm{Fe}-\mathrm{C}$ alloy

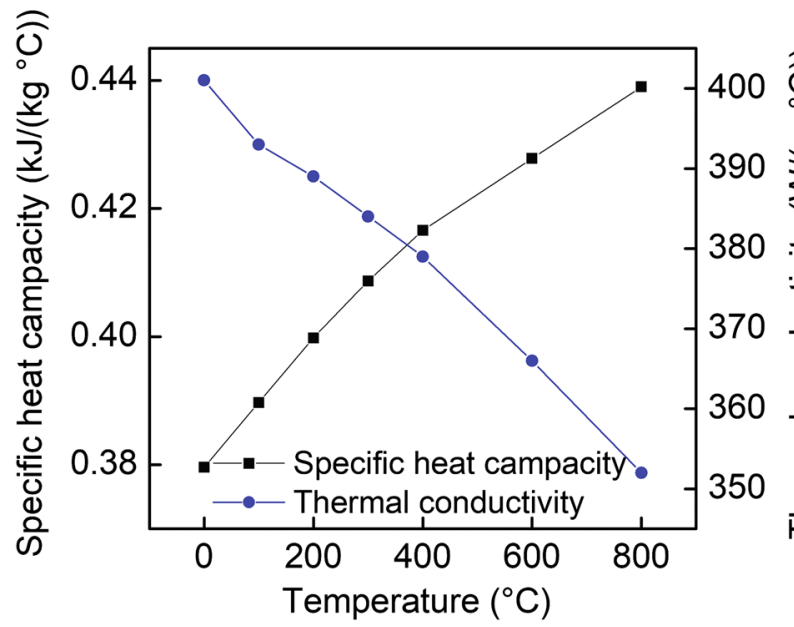

Fig. 6 Specific heat capacity and thermal conductivity of copper coil

where $T$ is the temperature, ${ }^{\circ} \mathrm{C} ; \lambda$ is the thermal conductivity, $\mathrm{W} /\left(\mathrm{m}{ }^{\circ} \mathrm{C}\right) ; \rho$ is the material density, $\mathrm{kg} / \mathrm{m}^{3} ; c$ is the specific heat capacity, $\mathrm{kJ} /\left(\mathrm{kg}{ }^{\circ} \mathrm{C}\right) ; q_{\mathrm{v}}$ is the internal heat source intensity, $\mathrm{W} / \mathrm{m}^{3} ; \tau$ is the time, $\mathrm{s}$. In this paper, only the positions and thickness of $\mathrm{Fe}-\mathrm{C}$ alloy blocking layer are calculated by numerical simulation and the induction heating is not involved, so the internal heat source $q_{\mathrm{v}}=0$.

\section{Results and Discussion}

\subsection{Measurement and Numerical Analysis of Coil Ambient Temperature}

\subsubsection{Heating Curve Design and Model Validation}

A ladle has to go through several stages during the actual production process in the steel plant: They are the ladle preheating stage, the containing molten steel stage, the refining stage, the standing and steel-teeming stage. In the preheating stage, the upper surface temperature of nozzle brick is $1000{ }^{\circ} \mathrm{C}$ approximately, and this stage lasts 120 min. After containing molten steel, the upper surface temperature of nozzle brick will reach $1600{ }^{\circ} \mathrm{C}$, and this temperature will last $120 \mathrm{~min}$ until the steel-teeming stage starts. The steel-teeming time is $40 \mathrm{~min}$. Therefore, to simulate the working condition, it is necessary to design an experimental heating curve for resistance furnace, as shown in Fig. 7. Firstly, the upper surface of nozzle brick is heated, the upper surface temperature of nozzle brick reaches $1000{ }^{\circ} \mathrm{C}$ after $60 \mathrm{~min}$, and the heat preservation time is $120 \mathrm{~min}$. After that, the upper surface of nozzle brick is heated to $1600{ }^{\circ} \mathrm{C}$ after $30 \mathrm{~min}$. After keeping this temperature for $120 \mathrm{~min}$, the maximal coil ambient temperature before the steel-teeming stage can be measured. After the measurement, the nozzle brick is cooled to room temperature naturally.

To verify the correctness of the numerical analysis model, this model was used to calculate the coil ambient temperature before steel-teeming stage. At the same time,

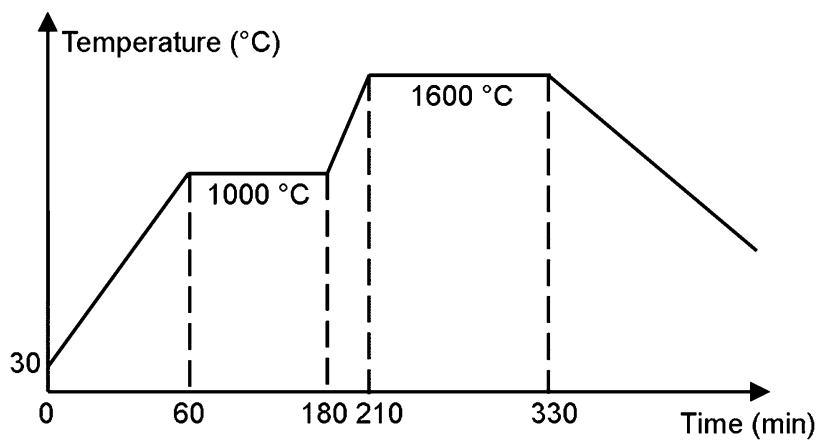

Fig. 7 Temperature curve of the upper surface of nozzle brick 
the coil ambient temperatures were measured by a $K$ thermocouple in the experiment. Experimental results are compared with numerical simulation results, as shown in Fig. 8. We can find that the change trend of numerical simulation results is consistent with that of experimental results, so the simulation model can be used to predict other process parameters.

In addition, from Fig. 8, the temperature growth rate on the upper side of induction coil increases gradually in the heating stage (Fig. 8a, c), and the main reason of this phenomenon is the large temperature difference caused by a rapid growth of the upper surface temperature of nozzle brick. In heat preservation stages (Fig. 8b, d), the temperature growth rate on the upper side of induction coil decreases gradually. The reason is that temperature distribution of the nozzle brick tends to thermal saturation because the upper surface temperature of nozzle brick is an invariant constant.

\subsubsection{Coil Ambient Temperatures Before Steel Teeming and After Steel Teeming}

After containing molten steel in the ladle, the coil ambient temperature increases continuously because of heat transfer from the high-temperature molten steel. When the containing time of molten steel is $120 \mathrm{~min}(t=330 \mathrm{~min})$, the temperature distribution of nozzle brick is shown in Fig. 9. It can be concluded that the temperature distribution from top to bottom in nozzle brick is gradient according to the calculation results. The heat conduction in $\mathrm{Fe}-\mathrm{C}$ alloy particles is faster than that of nozzle brick, because the thermal conductivity of $\mathrm{Fe}-\mathrm{C}$ alloy is larger than that of nozzle brick. At this time, the upper surface temperatures of induction coil obtained by numerical calculation and experimental measurement are 626 and $667{ }^{\circ} \mathrm{C}$, respectively. The numerical result is less than the experimental one slightly. The main reason is that there is a gap between

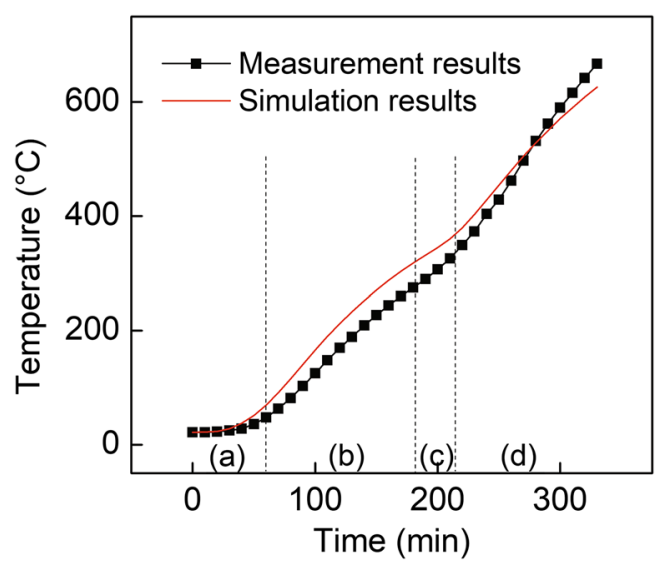

Fig. 8 Temperature variation curve of coil ambient temperature

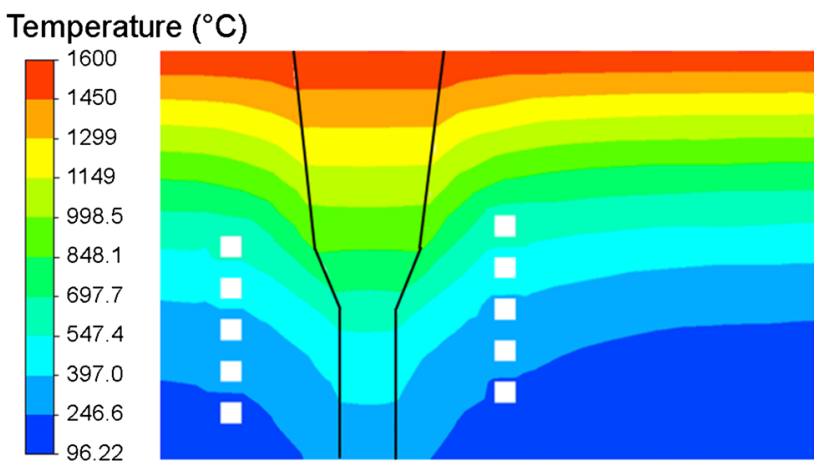

Fig. 9 Temperature distribution inside nozzle brick before steel teeming $(t=330 \mathrm{~min})$

four sides of nozzle brick and resistance furnace in the experiments, so four sides of nozzle brick will be heated at the same time when the upper surface of nozzle brick is heated. However, the four sides of nozzle brick are adiabatic during the simulation process. In the industrial test process, the errors caused by the above factors can be neglected. And as shown in Fig. 8, the errors between numerical results and experimental results are very small. Therefore, the numerical simulation method can predict the upper side temperature of induction coil in the nozzle brick.

After automatic steel teeming, high-temperature molten steel flows through nozzle brick and upper nozzle into the tundish. The working condition of induction coil will become worse, and the coil ambient temperature increases furtherly. As mentioned earlier, numerical simulation method can also calculate the coil ambient temperature approximately. Therefore, the temperature distribution of nozzle brick after molten steel containing time for $120 \mathrm{~min}$ and steel-teeming time for $40 \mathrm{~min}(t=370 \mathrm{~min})$ is shown in Fig. 10. At this time, the upper side temperature of induction coil is $791{ }^{\circ} \mathrm{C}$, which is very important to guide heat insulation and cooling of induction coil.

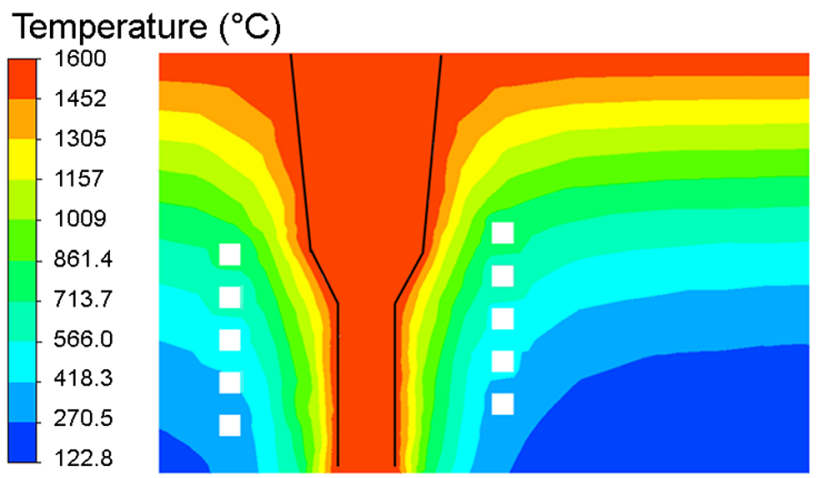

Fig. 10 Temperature distribution inside nozzle brick after steel teeming 


\subsection{Analysis of Position and Thickness of Fe-C Alloy Blocking Layer}

Refining temperature of different steel grades is different. And the containing time of molten steel in ladle also affects the temperature distribution of nozzle brick. These will affect the coil ambient temperature seriously and also affect the position and thickness of the $\mathrm{Fe}-\mathrm{C}$ alloy blocking layer. When the refining temperature of liquid steel was $1600{ }^{\circ} \mathrm{C}$, and the containing time of molten steel in ladle was $120 \mathrm{~min}$, the position and thickness of the $\mathrm{Fe}-\mathrm{C}$ alloy blocking layer were measured by sand-collection method and steel-pour method in industrial experiments. They were also calculated by numerical simulation. The experimental results are compared and analyzed with numerical results. After that, the criterion temperatures of the $\mathrm{Fe}-\mathrm{C}$ alloy blocking layer are corrected in numerical calculation.

\subsubsection{Experimental Results of Position and Thickness of Fe- C Alloy Blocking Layer}

The cost of sand-collection method is low, and this method has no influence on the normal steel production process. Therefore, this method is used to measure the height of the $\mathrm{Fe}-\mathrm{C}$ alloy original layer during the experimental process. When refining temperatures are 1500 and $1600{ }^{\circ} \mathrm{C}$, the results are shown in Fig. 11. The shape of the $\mathrm{Fe}-\mathrm{C}$ alloy particles is cylindrical, and their sizes are $2.0 \mathrm{~mm}: 2.0 \mathrm{~mm}$ (bottom diameter to height). The average height of the $\mathrm{Fe}-$ $\mathrm{C}$ alloy original layer is $243 \mathrm{~mm}$ when refining temperature of molten steel is $1500{ }^{\circ} \mathrm{C}$. That means that the distance between the lower surface of the blocking layer and the bottom of the upper slide plate is $243 \mathrm{~mm}$. Similarly, when refining temperature of molten steel is $1600{ }^{\circ} \mathrm{C}$, the average height of the $\mathrm{Fe}-\mathrm{C}$ alloy original layer is $231 \mathrm{~mm}$.

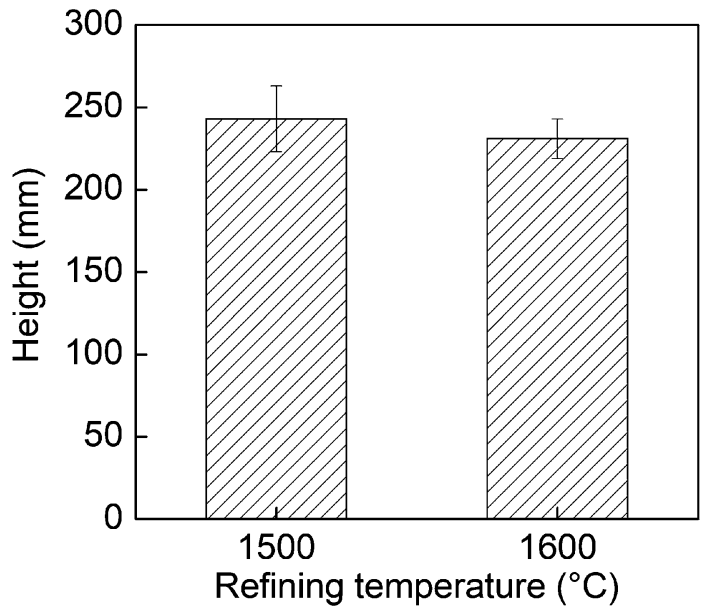

Fig. 11 Height of the $\mathrm{Fe}-\mathrm{C}$ alloy original layer at different refining temperatures
Obviously, the position of the $\mathrm{Fe}-\mathrm{C}$ alloy blocking layer moves downward with the increase of refining temperature of liquid steel.

The lower surface position of the $\mathrm{Fe}-\mathrm{C}$ alloy blocking layer can be measured by the sand-collection experiments, but the top surface position and thickness of the $\mathrm{Fe}-\mathrm{C}$ alloy blocking layer cannot be obtained by this method. In the sand-collection experiments, the lower surface position of the $\mathrm{Fe}-\mathrm{C}$ alloy blocking layer is lower relatively when refining temperature of molten steel is $1600{ }^{\circ} \mathrm{C}$. Therefore, the position of induction coil in the EICAST system needs to be designed according to a lower surface position of the blocking layer. After that, the EICAST system can be applied in all steel grades during the steel production process. Because of its high cost, the steel-pour method was only used to investigate the position and thickness of the $\mathrm{Fe}-\mathrm{C}$ alloy blocking layer when the refining temperature of molten steel is $1600{ }^{\circ} \mathrm{C}$. The experimental results show that the height $D_{1}$ of the Fe-C alloy melting layer is $154 \mathrm{~mm}$, which means that the 154-mm Fe-C alloy particles at the top of the upper nozzle are melted completely. The height $D_{2}$ of the Fe-C alloy original layer is $231 \mathrm{~mm}$, which means that the $231-\mathrm{mm} \mathrm{Fe}-\mathrm{C}$ alloy particles at the bottom of the upper nozzle are not sintered, and they can fall freely after the sliding gate is opened. Therefore, the thickness of the $\mathrm{Fe}-\mathrm{C}$ alloy blocking layer can be calculated, and it is $130 \mathrm{~mm}$. The results are consistent with those obtained by sand-collection method. Based on the above results, the position and thickness of the $\mathrm{Fe}-\mathrm{C}$ alloy blocking layer can be obtained, as shown in Fig. 12.

\subsubsection{Numerical Analysis of Fe-C Alloy Blocking Layer}

Temperature distribution of $\mathrm{Fe}-\mathrm{C}$ alloy is gradient because of heat transfer from high-temperature molten steel in ladle. The temperature of $\mathrm{Fe}-\mathrm{C}$ alloy increases with the increase of containing time of molten steel. Therefore, the temperature distributions at the centerline of $\mathrm{Fe}-\mathrm{C}$ alloy after different containing time of molten steel were

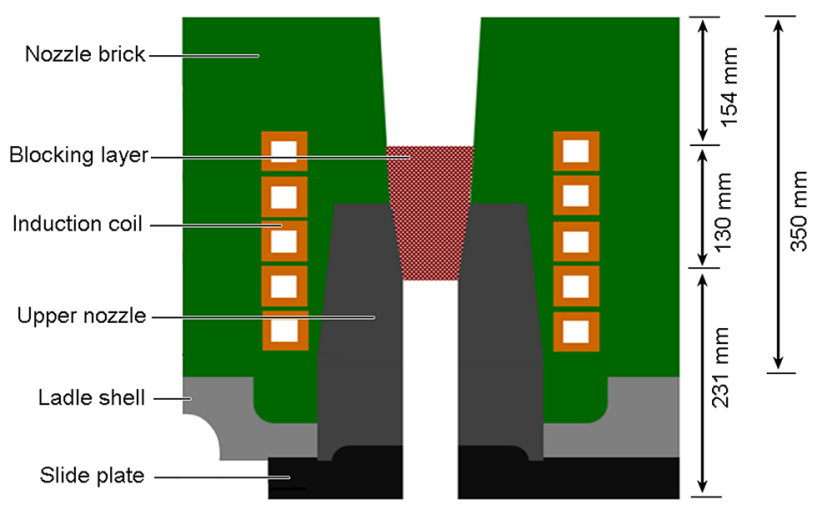

Fig. 12 Position and thickness of the Fe-C alloy blocking layer 
calculated by numerical simulation, as shown in Fig. 13 . With the increase of containing time of molten steel, the temperature of $\mathrm{Fe}-\mathrm{C}$ alloy increases gradually, but the growth rate of temperature decreases gradually. Compared with the temperature of $\mathrm{Fe}-\mathrm{C}$ alloy when the containing time of molten steel is $120 \mathrm{~min}(t=330 \mathrm{~min})$, the temperature rise of $\mathrm{Fe}-\mathrm{C}$ alloy is not obvious when the containing time of molten steel is $180 \mathrm{~min}(t=390 \mathrm{~min})$.

In addition, it can be found from Fig. 13, when the containing time of molten steel is $120 \mathrm{~min}(t=330 \mathrm{~min})$, the temperature distribution from top to bottom of $\mathrm{Fe}-\mathrm{C}$ alloy is gradient because of heat conduction from hightemperature molten steel. Melting point of $\mathrm{Fe}-\mathrm{C}$ alloy in Table 1 is $1505{ }^{\circ} \mathrm{C}$, and sintering temperature of $\mathrm{Fe}-\mathrm{C}$ alloy is $900{ }^{\circ} \mathrm{C}$ [28]. If the melting point and sintering temperature of $\mathrm{Fe}-\mathrm{C}$ alloy are used as criterion standard to confirm the position and thickness of $\mathrm{Fe}-\mathrm{C}$ alloy blocking layer, the thickness of blocking layer is $127 \mathrm{~mm}$, the distance between the top surface of blocking layer and the top surface of nozzle brick is $31 \mathrm{~mm}$, and the distance between bottom surface of blocking layer and bottom surface of nozzle brick is $192 \mathrm{~mm}$. Compared with the results obtained by sand-collection method and steel-pour method, these results about $\mathrm{Fe}-\mathrm{C}$ alloy blocking layer have a big difference. Therefore, according to the experimental results, it is necessary to correct the criterion temperatures of $\mathrm{Fe}-\mathrm{C}$ alloy blocking layer after numerical calculation.

The reasons for the difference between the experimental results and simulation results are shown in Fig. 14. After the heat transfer from liquid steel, there is an $\mathrm{Fe}-\mathrm{C}$ alloy transition layer between melted layer and sintered layer. And the temperature of the transition layer is lower than the melting point of $\mathrm{Fe}-\mathrm{C}$ alloy particles in numerical simulation. However, the transition layer is mainly composed of

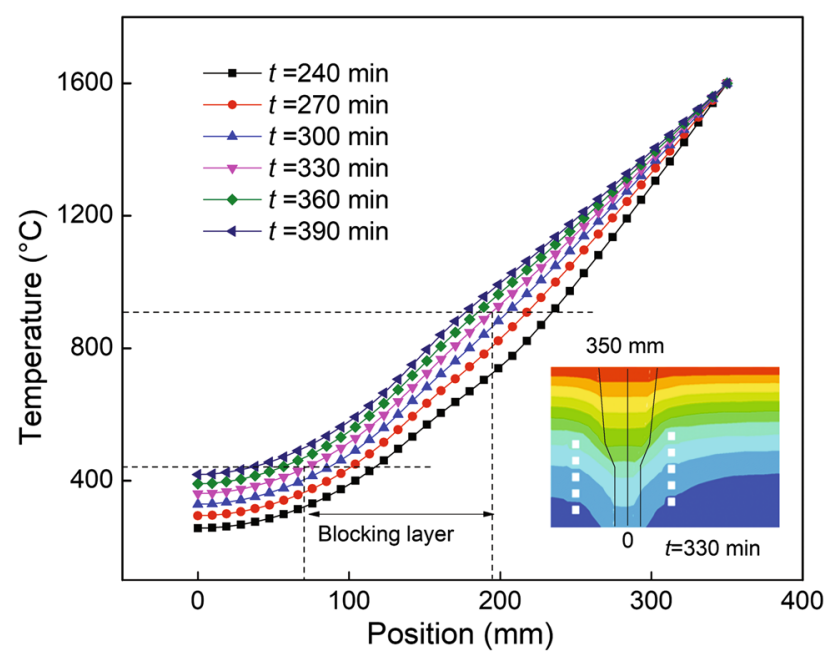

Fig. 13 Temperature variation of $\mathrm{Fe}-\mathrm{C}$ alloy at different time

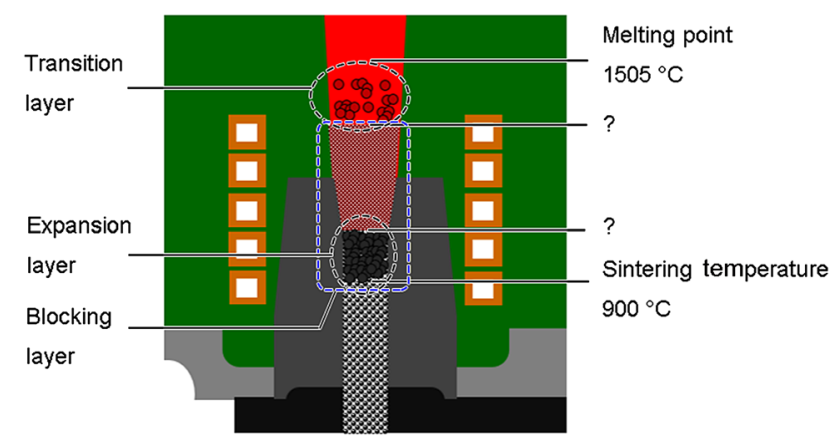

Fig. 14 Mechanism analysis of thickness and position difference of blocking layer

$\mathrm{Fe}-\mathrm{C}$ alloy particles, interstitial molten steel, and $\mathrm{Fe}-\mathrm{C}$ alloy sintered clusters, which cannot block the molten steel. In the steel-pour experiments, the $\mathrm{Fe}-\mathrm{C}$ alloy transition layer will flow out with liquid steel. Therefore, it is wrong to determine the upper surface position of the blocking layer by the melting point of $\mathrm{Fe}-\mathrm{C}$ alloy. However, because of the limited experimental conditions, the $\mathrm{Fe}-\mathrm{C}$ alloy transition layer cannot be measured. For the lower surface of the blocking layer, when the ambient temperature exceeds a certain value, the $\mathrm{Fe}-\mathrm{C}$ alloy particles will expand and the friction between them will increase, which lead to a result that the expanded $\mathrm{Fe}-\mathrm{C}$ alloy particles cannot fall down automatically. After opening the sliding gate, under the sintering layer, there are some expanded $\mathrm{Fe}-\mathrm{C}$ alloy particles, which cannot drop automatically, and they are also a part of blocking layer. There is an $\mathrm{Fe}-\mathrm{C}$ alloy expansion layer between sintered layer and original layer. Therefore, the lower surface position of the $\mathrm{Fe}-\mathrm{C}$ alloy blocking layer cannot be determined by the $\mathrm{Fe}-\mathrm{C}$ alloy sintering temperature. Compared with the experimental results, after numerical calculation, the criterion temperatures of $\mathrm{Fe}-\mathrm{C}$ alloy blocking layer are $919{ }^{\circ} \mathrm{C}$ (the upper surface temperature of blocking layer) and $428^{\circ} \mathrm{C}$ (the lower surface temperature of blocking layer), as shown in Fig. 15. By these criterion temperatures, the simulation results about position and thickness of the $\mathrm{Fe}-\mathrm{C}$ alloy blocking layer are in agreement with the experimental results.

As mentioned earlier, the containing time of molten steel in ladle is an important factor affecting the position and thickness of the $\mathrm{Fe}-\mathrm{C}$ alloy blocking layer. For different steel grades, the refining process and refining time are different, which leads to different containing time of molten steel. After different containing time of molten steel, the position and thickness of the $\mathrm{Fe}-\mathrm{C}$ alloy blocking layer are shown in Fig. 16. It shows that with the increase of the containing time of molten steel, the position of the $\mathrm{Fe}-\mathrm{C}$ alloy blocking layer moves downward gradually, 


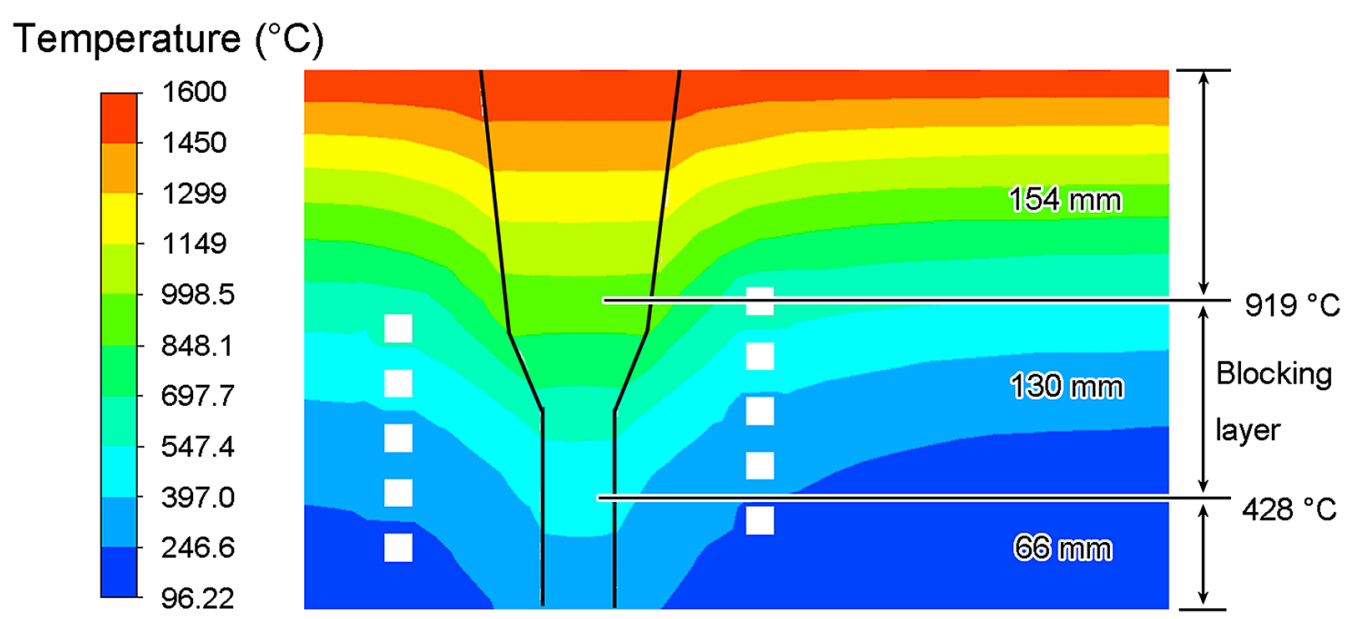

Fig. 15 Criterion temperatures of $\mathrm{Fe}-\mathrm{C}$ alloy plugging layer

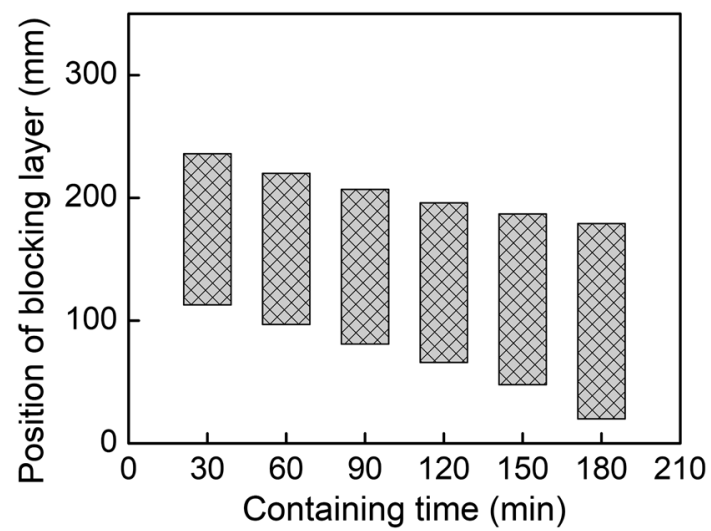

Fig. 16 Position of $\mathrm{Fe}-\mathrm{C}$ alloy blocking layer after different containing time

which is beneficial to the installation of induction coil in nozzle brick. However, long containing time of molten steel will lead to an increase in the thickness of the blocking layer, which is detrimental to the installation of induction coil. Therefore, when the containing time of molten steel is too short or too long, the position and thickness of the $\mathrm{Fe}-\mathrm{C}$ alloy blocking layer need to be adjusted by other ways. However, the $\mathrm{C}$ content in $\mathrm{Fe}-\mathrm{C}$ alloy has a significant influence on the melting point of $\mathrm{Fe}-$ $\mathrm{C}$ alloy. With the increase of $\mathrm{C}$ content, the melting point of $\mathrm{Fe}-\mathrm{C}$ alloy decreases obviously [29]. Therefore, when the containing time of molten steel is certain, the $\mathrm{Fe}-\mathrm{C}$ alloy composition can be adjusted to ensure the position and thickness of the $\mathrm{Fe}-\mathrm{C}$ alloy blocking layer within a suitable range, which can guide the installation of induction coil. These are important for the wide application of the EICAST technology.

\section{Conclusions}

By the experiments in the large experimental platform and in the steel plant, the coil ambient temperature and the position of $\mathrm{Fe}-\mathrm{C}$ alloy blocking layer were measured. Numerical simulation results about those were also verified and corrected. Main conclusions are as follows:

1. Coil ambient temperature increases with the increase of containing time of molten steel in ladle. When the upper surface temperature of nozzle brick reaches $1600{ }^{\circ} \mathrm{C}$ and maintains $120 \mathrm{~min}$, the upper surface temperature of induction coil will reach $626{ }^{\circ} \mathrm{C}$.

2. After containing molten steel for $120 \mathrm{~min}$ and steel teeming for $40 \mathrm{~min}$, the working environment of induction coil is the worst, and the coil ambient temperature will reach $791{ }^{\circ} \mathrm{C}$, which provides a theoretical basis for the design of insulation and cooling.

3. By sand-collection method and steel-pour method, the position and thickness of $\mathrm{Fe}-\mathrm{C}$ alloy blocking layer in a $110 \mathrm{t}$ ladle were measured. The thickness of blocking layer is $130 \mathrm{~mm}$, the distance between the upper surface of blocking layer and the upper surface of nozzle brick is $154 \mathrm{~mm}$, and the distance between the lower surface of blocking layer and the lower surface of upper slide gate is $231 \mathrm{~mm}$. Compared with the experimental results, the criterion temperatures of the $\mathrm{Fe}-\mathrm{C}$ alloy blocking layer in numerical simulation are modified to 919 and $428{ }^{\circ} \mathrm{C}$.

4. Containing time of molten steel can change the position and thickness of the blocking layer. The $\mathrm{C}$ content can be adjusted to change the melting point of the $\mathrm{Fe}-\mathrm{C}$ alloy, and the position and thickness of the $\mathrm{Fe}-\mathrm{C}$ alloy blocking layer can be adjusted by this way. 
Acknowledgements This work was financially supported by the National Natural Science Foundation of China (Grant No. U1560207).

\section{References}

[1] Y. Hou, Z.Q. Zhang, W.D. Xuan, J. Wang, J.B. Yu, Z.M. Ren, Acta Metall. Sin. (Engl. Lett.) 31, 681 (2018)

[2] F.P. Tang, D.G. Li, X.W. Liao, X.F. Wang, X.F. Wan, J.X. Jia, J.G. Zhang, J. Iron Steel Res. Int. 18, 9 (2011)

[3] G.G. Cheng, M.L. Wang, X.E. Yang, Y.L. Li, Y.G. Wang, L.Y. Wang, P. Zhao, Acta Metall. Sin. (Engl. Lett.) 16, 379 (2003)

[4] H.J. Visser, R. Boom, ISIJ Int. 46, 1771 (2006)

[5] Z.Y. Lai, Z. Xie, L.C. Zhong, ISIJ Int. 48, 793 (2008)

[6] D.P. Tan, P.Y. Li, X.H. Pan, J. Iron Steel Res. Int. 16, 1 (2009)

[7] L. Cheng, W.G. Pang, K.Y. Peng, D.Z. Liu, W.Q. Shi, X.H. Peng, China Metall. 23, 31 (2013)

[8] L.F. Zhang, B.G. Thomas, X.H. Wang, K. Cai, in 85th Steelmaking Conference Proceedings, ISS-AIME, Warrendale, PA, vol. 431 (2002)

[9] J. Yang, China Pat. CN104690241A (2015)

[10] W.D. Liu, China Pat. CN102218527A (2011)

[11] Y.L. Sun, Y.Z. Luo, X.C. Jia, Cont. Cast. 41, 23 (2016)

[12] Y.F. Huang, P.Y. Du, Y.S. Li, Refract 40, 433 (2006)

[13] F. Farshidfar, M.G. Kakroudi, J. Iron. Steel Res. Int. 19, 11 (2012)

[14] C. Zhang, Z. Li, L.Y. Zhu, Y.K. Xie, Cont. Cast. (China) 42, 46 (2017)

[15] J.H. He, W.D. Qiu, Y.H. Liang, J.H. Nie, Y.C. Yin, Refract 48, 74 (2014)
[16] J.H. Zhu, S.L. Chen, S.H. Zhou, H.P. Zhang, Cont. Cast. 4, 43 (2005)

[17] H.X. Zhu, C.J. Deng, C. Bai, W.G. Zhang, Steelmaking 24, 49 (2008)

[18] G.J. Wang, X.M. Li, Y.H. Pan, J. Hong, Z.B. Guo, M. Zhang, Steelmaking 23, 24 (2007)

[19] D.J. Li, Q. Wang, X.A. Liu, A. Gao, X.B. Wang, J. Dong, K. Marukawa, J.C. He, J. Iron. Steel Res. Int. 19, 766 (2012)

[20] Q. Wang, D.J. Li, X.A. Liu, X.B. Wang, J. Dong, J.C. He, J. Iron. Steel Res. Int. 22, 30 (2015)

[21] M. He, Q. Wang, X.A. Liu, C.Y. Shi, T. Liu, J.C. He, High Temp. Mater. Proc. 36, 441 (2017)

[22] Q. Wang, J.C. He, T. Liu, New Technologies of Electromagnetic Metallurgy (Science Press, Beijing, 2015), p. 90

[23] A. Gao, Q. Wang, D.J. Li, B.G. Jin, K. Wang, J.C. He, Acta Metall. Sin. 46, 634 (2010)

[24] X.A. Liu, Q. Wang, D.J. Li, G.L. Li, D.Q. Geng, A. Gao, J.C. He, ISIJ Int. 54, 482 (2014)

[25] M. He, X.L. Li, Z.Q. Cao, S.L. Dong, T. Liu, Q. Wang, Vacuum 146, 130 (2017)

[26] W.H. Tong, F.M. Shen, H. Shibata, W.Z. Wang, Y.S. Yang, Y. Waseda, R. Takahashi, J.I. Yagi, Acta Metall. Sin. 38, 983 (2002)

[27] S.M. Yang, W.Q. Tao, Heat Transfer (Higher Education Press, Beijing, 2006), p. 555

[28] A. Gao, D.J. Li, Q. Wang, K. Wang, B.G. Jin, K. Marukawa, J.C. He, ISIJ Int. 50, 1770 (2010)

[29] A. Gao, Q. Wang, D.J. Li, H.S. Chai, L.J. Zhao, J.C. He, Acta Metall. Sin. 47, 219 (2011) 